\title{
Effects of Silane on the Push-out Bond Strength of Fiber-reinforced Resin Posts luted with different Self-adhesive Resin Cements
}

\author{
1'Zsolt Rajnics, ${ }^{2}$ Gyula Marada, ${ }^{3}$ El-Hag Moetaz, ${ }^{4}$ Márta Radnai
}

\section{ABSTRACT}

Aim: The present study was completed to evaluate the effect of silane on the push-out bond strength on fiber-reinforced posts. The intention of the study was also to determine if there was a regional relation between the adhesive system and the push-out bond strength of the fiber post.

Materials and methods: Fifteen single rooted human teeth were endodontically treated and $2 \mathrm{~mm}$ diameter glass fiberreinforced composite posts were cemented in the root canal. In the first group Futurabond DC without silane, in the second group the same luting material after silane treatment of the posts, and in the third group Clearfil DC Core System without silane were used to lute the posts.

After complete setting of the luting agents three 2-mm-thick slices were obtained from the cervical, middle, and apical regions of the roots. The specimens were subjected to push-out test in special equipment. Bond strength data were analyzed with analysis of variance tests.

Results: The Rebilda posts cemented with Futurabond DC without silane had the highest push-out bond strength at the coronal region (164.71 $\mathrm{N} \pm 72.12$ ), while the posts cemented with Clearfil without silane had the lowest value at the apical region (94.86 $\mathrm{N} \pm 34.14)$. Silane had no significance on the push-out bond strength ( $p=0.909)$; however, the root canal dentin regions had a significant effect $(p<0.010)$.

Conclusion: This study did not show any significant differences among different luting protocols. The bond strength was significantly higher in the coronal region due to the greater cemented surface area and the difference in dentin structure.

Clinical significance: Based on the results of the push-out tests, the retention of the posts did not depend on the luting methods; however, the region of the root canal played a significant role.

Keywords: Fiber-reinforced resin post, Push-out test, Silane.

How to cite this article: Rajnics Z, Marada G, Moetaz E, Radnai M. Effects of Silane on the Push-out Bond Strength of Fiber-reinforced Resin Posts luted with different Self-adhesive Resin Cements. Int J Experiment Dent Sci 2017;6(1):22-25.

${ }^{1}$ Lecturer, ${ }^{2}$ Senior Lecturer, ${ }^{3}$ Private Practitioner, ${ }^{4}$ Professor and Chair

${ }^{1,2,4}$ Division of Prosthodontics, Faculty of Dentistry, Oral and Maxillofacial Surgery, University of Pécs Medical School, Pécs Baranya, Hungary

${ }^{3}$ Department of Prosthodontics, Faculty of Dentistry, University of Pécs, Beleville, Ontario, Canada

Corresponding Author: Zsolt Rajnics, Lecturer, Division of Prosthodontics, Faculty of Dentistry, Oral and Maxillofacial Surgery University of Pécs Medical School, Pécs, Baranya, Hungary Phone: +003672536000, e-mail: zsolt.rajnics@gmail.com
Source of support: Nil

Conflict of interest: None

\section{INTRODUCTION}

The preservation of endodontically treated teeth is of great importance. Post and cores are used to restore endodontically treated teeth when there is an extensive loss of the tooth structure. The goals of post and core treatment are to maintain coronal and apical seal of the root canal, protect and preserve the remaining tooth structure, provide a supportive and retentive foundation for the placement of the definitive restoration, and to restore function and esthetics. ${ }^{1,2}$

Posts are traditionally divided into prefabricated and casted. The casted posts require temporary restoration of the root canal after root canal preparation and risk reinfection of the canal due to coronal leakage. The prefabricated posts can be luted immediately after root canal preparation in one appointment. ${ }^{1,3}$ Fiber-reinforced resin posts with resin cements are widely used as a prefabricated post technology. Fiber posts have a similar modulus of elasticity (16-40 GPa) to dentin (18.6 GPa), allowing for uniform stress distribution and decrease in stress concentration at the restorative interface. ${ }^{4,5}$ In vitro and in vivo studies show that the better stress distribution of prefabricated fiber posts compared with casted metal posts reduces the tendency of vertical root fractures. ${ }^{6,7}$

Failure of fiber post restored teeth occurs mainly due to debonding of the post at the post-cementation junction. ${ }^{8}$ Many factors can affect the retention of the post within the root canal. A few of the aforementioned factors include the type of post, adhesive and cementation system, operative procedures, and the configuration of the root system. ${ }^{9}$

Among others, the type of post, adhesive and cementation system, operative procedures, and the configuration of the root system may affect the retention of the post within the root canal.

In an attempt to increase the bond strength of the post-cementation junction, silane-coupling agents are used. Silane has functional groups that allow covalent adhesion between the quartz fibers of the posts and 
the core resin matrix. Studies prove that silanization improves the bond strength between the fiber posts and the resin cements. ${ }^{8}$

Dentin is a dynamic tissue that changes with age, due to caries and restorative procedures. The histological structure of dentin also alters regionally from the coronal down to the apical portion. ${ }^{10}$ These factors along with the difficulty of reaching the apical portion of roots with restorative materials can alter the retention of the post in the root canal. ${ }^{11}$

The present study was completed to evaluate the effect of silane on the push-out bond strength on fiberreinforced posts. The intention of the study was also to determine if there was a regional relation between the adhesive system and the push-out bond strength of the fiber post. In regard to silane, the null hypothesis was that silane treatment of the post would not affect the pushout bond strength. The second null hypothesis stated that there was no regional relation in terms of push-out bond strength.

\section{MATERIALS AND METHODS}

In this in vitro study, 15 single-rooted extracted human teeth were used. The teeth were submerged in $6 \%$ formalin solution for 1 hour. After the formalin treatment, all the specimens were placed in a sterile saline solution for 3 days. The selected roots were fully developed, about $15 \mathrm{~mm}$ long, caries free, without fracture and resorption. The morphology of the roots allowed the placement of a $10 \mathrm{~mm}$ long prefabricated fiber-reinforced resin post.

The crown of each specimen was sectioned at the cementoenamel junction (CEJ) using a diamond bur and water cooling. The pulp tissue was exposed and removed with nickel-titanium Donaldson files (VDW $\mathrm{GmbH}$, Munich, Germany). Thereafter, all root canals were prepared with nickel-titanium K-files (VDW $\mathrm{GmbH}$, Munich, Germany) (\#40 size at apical seal). Each enlargement was followed by chemical irrigation with $2.5 \%$ sodium hypochlorite. The prepared roots were dried by paper points (Shanghai Dochem Industries, Shanghai, China) and filled with gutta-percha cones (Shanghai Dochem Industries, Shanghai, China) using lateral condensation technique and resin sealer (AH Plus, Dentsply York PA, USA).

After endodontic treatment, each root canal opening was filled with light-curing temporary filling material (Clip F, VOCO GmbH, Cuxhaven, Germany) and stored in sterile saline for 3 days at room temperature.

After storage period, the temporary filling material was removed with diamond burs. The gutta-percha was removed with Gates-Glidden files (VDW GmbH, Munich, Germany), leaving $4 \mathrm{~mm}$ of the root canal filling at the apical end. Using the $1.2 \mathrm{~mm}$ diameter drill, belonging to Rebilda Post System (VOCO GmbH, Cuxhaven, Germany) package, the roots were drilled to a depth of $10 \mathrm{~mm}$ with water cooling. The root canals were enlarged using the 1.5 and $2 \mathrm{~mm}$ diameter drill. During instrumentation, the root canals were irrigated with $2.5 \%$ sodium hypochlorite solution.

Once all the root canals were enlarged, the root canals were dried using paper points. All the roots were prepared with the same method. The specimens were then randomly divided into three groups of five specimens each:

- Group I: The posts were luted using Futurabond DC (VOCO GmbH, Cuxhaven, Germany) without treating the posts with silane - labeled 1 to 5 .

- Group II: The posts were luted using Futurabond DC (VOCO GmbH, Cuxhaven, Germany) and silane (Ceramic Bond, VOCO GmbH, Cuxhaven, Germany) labeled 6 to 10 .

- Group III: The posts were luted using Clearfil DC Core System (Kuraray Noritake Dental Inc., Sakazu, Okayama, Japan) without treating the post with silane - labeled 11 to 15 .

In each specimen group, a $2 \mathrm{~mm}$ diameter glass fiberreinforced composite post (VOCO $\mathrm{GmbH}$, Cuxhaven, Germany) was cemented in the root canal. In groups I and II, the root canal dentin walls were conditioned using Futurabond DC - dual-cured self-etch bond (VOCO $\mathrm{GmbH}$, Cuxhaven, Germany) before cementation of the posts. The bond was applied to the root canal for 20 seconds using a microbrush. The post space was then dried using paper points. Group III followed the same procedures but used Clearfil S3 Bond Plus (Kuraray Noritake Dental Inc., Sakazu, Okayama, Japan) technology.

For cementation of the posts, Rebilda DC dual-cure core build-up composite, Rebilda DC (VOCO GmbH, Cuxhaven, Germany), was used for groups I and II. For group III, Clearfil DC core plus dual cement (Kuraray Noritake Dental Inc., Sakazu, Okayama, Japan) was used. The cements were applied using an automix syringe and mixing tips. The posts were then inserted using pressure to the $10 \mathrm{~mm}$ depth. Excessive cement was disposed. The resin cements were light cured for 60 seconds. After cementation, each group was placed into three marked jars of room temperature sterile saline.

Using a diamond disk and water cooling, each root specimen from the aforementioned groups was sectioned into three sections starting $2 \mathrm{~mm}$ below the CEJ: coronal, middle, and apical. Each section was of $2 \mathrm{~mm}$ thickness. The coronal section was labeled using the letter $\mathrm{A}$, middle with the letter $\mathrm{B}$, and apical using the letter $\mathrm{C}$ (e.g., coronal section of the first root of first group was labeled 1A, while 
apical slice of second root of third group was labeled 12C). Each section was placed into labeled Eppendorf sample tubes containing sterile saline.

The sections were then individually loaded on a Lloyd $1000 \mathrm{R}$ materials testing machines. The machine pushed out the post fragments from each specimen to determine the peak force. The diameter of the push-out pin was $1 \mathrm{~mm}$ and the cross-head speed was $0.5 \mathrm{~mm} /$ minute during the tests. The machine measured the loading force according to movements. During the measurement, it calculated and drew a graph in which the x-axis showed the movement in $\mathrm{mm}$ and the $\mathrm{y}$-axis showed the applied force in Newton. From the graphs the computer calculated the biggest applied force. The results were analyzed with one-way analysis of variance test.

\section{RESULTS}

Sample 1B, 5A, 5C, 8A, 11B, 13A, 15A, and 15C were pushed out with minimal force and minimal resistance. The diameter of the post for samples $8 \mathrm{C}, 9 \mathrm{C}$, and $10 \mathrm{C}$ was smaller than the diameter of the push-out pin; therefore, it was not able to push out the post fragments. Sample 11A was unable to fit into the sample holder. Due to experimental errors, these specified results were omitted from further calculations. Some other slices were fractured during sectioning and left out from the push-out test.

The overall push-out bond strength mean values are shown in Table 1 and Graph 1. The luting with Futurabond DC without silane had the highest mean push-out bond strength at the coronal region, while the luting with Clearfil without silane had the lowest mean value at the apical region.

Comparison of Futurabond without silane and Futurabond with silane technologies to evaluate the effect on retention showed that use of silane had no significant effect $(p=0.909)$ on the push-out bond strength. Evaluation of regional retention for all the samples showed that root canal dentin region influenced significantly $(p=0.010)$ the push-out bond strength.

Table 1: Descriptive statistics and push-out bond strengths $(\mathrm{N})$ and standard deviations for different surface treatments of the posts and different luting agents

\begin{tabular}{llll}
\hline Treatment & Region & Specimen $(n)$ & Mean $(n \pm$ SD) \\
\hline Futurabond DC & Coronal (A) & 4 & $164.71 \pm 72.12$ \\
without silane & Middle (B) & 4 & $137.81 \pm 39.25$ \\
& Apical (C) & 4 & $98.56 \pm 48.52$ \\
Futurabond DC & Coronal (A) & 4 & $137.48 \pm 30.13$ \\
with silane & Middle (B) & 5 & $135.09 \pm 59.03$ \\
& Apical (C) & 2 & $121.27 \pm 121.27$ \\
Clearfil DC & Coronal (A) & 2 & $158.08 \pm 89.88$ \\
without silane & Middle (B) & 4 & $155.22 \pm 15.84$ \\
& Apical (C) & 4 & $94.87 \pm 34.15$ \\
\hline
\end{tabular}

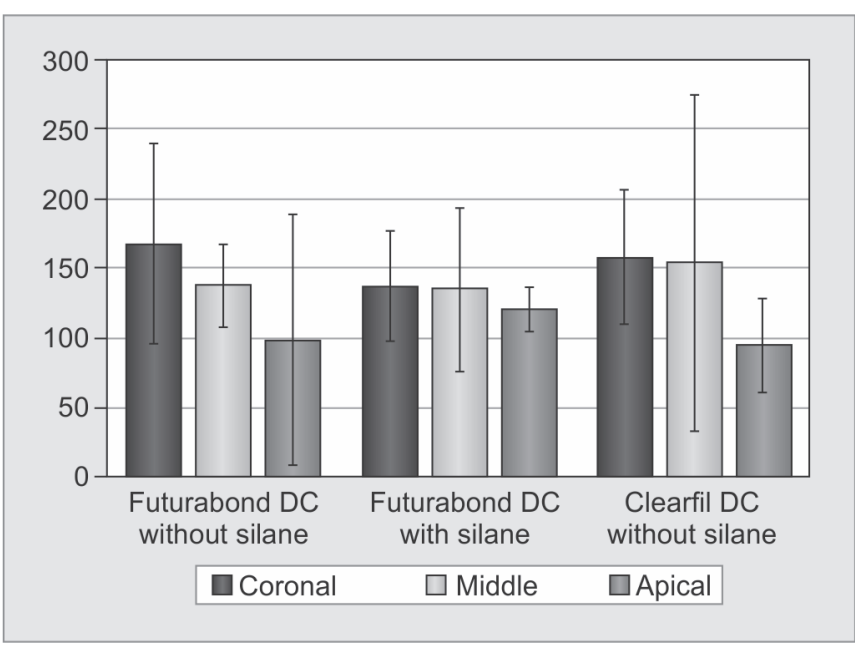

Graph 1: Mean push-out bond strengths ( $n$ ) and standard deviations using different luting technologies

\section{DISCUSSION}

Our findings suggest that using a silane-coupling agent on a glass fiber-reinforced resin post had no statistically significant effect on the push-out bond strength between the fiber post and resin cement. Within the limitations of the study, the results confirmed that root canal dentin regions had a significant effect on the push-out bond strength.

Fiber posts are made of resin matrix surrounded by various types of fibers. In terms of glass fiber posts, the matrix is made up of epoxy resin, while the fibers are made of glass. ${ }^{12}$ Epoxy polymers cannot bond chemically with composite resin cements because of their highly cross-linked structure. ${ }^{13}$ To increase the push-out bond strength between the post and the resin cement, some authors suggested using silane-coupling agents on the post. ${ }^{14}$ A study by Perdigão et al ${ }^{15}$ confirmed our results and showed no statistically significant effect on the pushout bond strength when using silane-coupling agents in concurrence with Wrbas et al, ${ }_{1}^{16}$ who also concluded silane as having no effect on push-out bond.

Silane adheres to the resin matrix of the post using covalent bonds. It also attaches between the glass fibers of the posts. ${ }^{14}$ Silane alone was found to have no significant effect on the bond strength of fiber post to resin cements. However, roughing the surface of a post with micromechanical procedures prior to using silane allows for the glass fibers to be in better contact with the coupling agent. ${ }^{13}$ Studies have shown treating the post with hydrogen peroxide prior using silane dissolves the surface epoxy matrix and roughens the post surface, which significantly improves the push-out bond strength. ${ }^{17}$

The adhesive system is commonly used in coronal enamel and dentin structures; however, their effect on 
intraradicular dentin is less understood. According to our results, the push-out strength was the largest in the coronal region of the root and decreased while moving apically, which was in accordance with several other studies. ${ }^{11,18,19}$

Various root regions show different distributions and densities of dentin tubules. The density and number of dentinal tubules decrease from coronal to apical regions of the roots. ${ }^{20}$ It is also observed that the diameter of the coronal dentin tubules is larger compared with the middle and apical regions. ${ }^{21}$ Therefore, various regions of the root canal react differently to acid etching. Apical root dentin is a less favorable bonding site as it has a lower number of dentinal tubules, irregular secondary dentin, cementum-like tissue on the root canal walls, and numerous accessory canals. ${ }^{20}$

The mechanism of adhesive bonding to root dentin relies heavily on resin tag formation accounting for $30 \%$ of total bond strength. ${ }^{22}$ Since there are fewer dentinal tubules in the apical region, there will be fewer resin tags formed, resulting in weaker bond strength. Additionally, better access to the coronal portion of the canal allows for the adhesive materials and light to be applied more thoroughly. ${ }^{15,21}$

The current study was an in vitro study and had some limitations. The test subjects did not have the crowns restored and neither thermal cycling nor mechanical stressing was applied. In addition, problems with the machinery and a small sample size may have contributed to the results obtained.

\section{CONCLUSION}

While the results of this study showed that silanecoupling agent had no significant effect on the push-out bond strength, further investigation with a larger sample size needs to be undertaken before a firm conclusion can be made. Within the limitations of the in vitro study, it can be concluded that the dentin root regions affect the push-out bond strength.

\section{CLINICAL SIGNIFICANCE}

Based on the results of the push-out tests, the retention of the posts did not depend on the luting methods; however, the region of the root canal played a significant role.

\section{REFERENCES}

1. William P, Johnson M. Color atlas of endodontics. Philadelphia (PA): Saunders; 2002.

2. Peroz I, Blankenstein F, Lange KP, Naumann M. Restoring endodontically treated teeth with posts and cores - a review. Quintessence Int 2005 Oct;36(9):737-746.

3. Assif D, Bitenski A, Pilo R, Oren E. Effect of post design on resistance to fracture of endodontically treated teeth with complete crowns. J Prosthet Dent 1993 Jan;69(1):36-40.
4. Schwartz RS, Robbins JW. Post placement and restoration of endodontically treated teeth: a literature review. J Endod 2004 May;30(5):289-301.

5. Christensen GJ. Posts and cores: state of the art. J Am Dent Assoc 1998 Jan;129(1):96-97.

6. Goracci C, Ferrari M. Current perspectives on post systems: a literature review. Aust Dent J 2011 Jun;56(1):77-83.

7. Dietschi D, Duc O, Krejci I, Sadan A. Biomechanical considerations for the restoration of endodontically treated teeth: a systematic review of the literature, Part II (Evaluation of fatigue behavior, interfaces, and in vivo studies). Quintessence Int 2008 Feb;39(2):117-129.

8. Kim HD, Lee JH, Ahn KM, Kim HS, Cha HS. Effect of silane activation on shear bond strength of fiber-reinforced composite post to resin cement. J Adv Prosthodont 2013 May;5(2): 104-109.

9. Gomes GM, Gomes OM, Reis A, Gomes JC, Loguercio AD, Calixto AL. Regional bond strengths to root canal dentin of fiber posts luted with three cementation systems. Braz Dent J 2011 Jul;22(6):460-467.

10. Mjör IA, Nordahl I. The density and branching of dentinal tubules in human teeth. Arch Oral Biol 1996 May;41(5): 401-412.

11. Akgungor $G, A k k a y a n ~ B$. Influence of dentin bonding agents and polymerization modes on the bond strength between translucent fiber posts and three dentin regions within a post space. J Prosthet Dent 2006 May;95(5):368-378.

12. Bateman G, Ricketts DNJ, Saunders WP. Fibre-based post systems: a review. Br Dent J 2003 Jul;195(1):43-48.

13. Monticelli F, Osorio R, Albaladejo A, Aguilera FS, Tay FR, Ferrari M, Toledano M. Effect of adhesive systems and surface treatment of methacrylate resin-based fiber posts on postresin-dentin bonds. Am J Dent 2007 Aug;20(4):231-234.

14. Park SJ, Jin JS. Effect of silane coupling agent on interphase and performance of glass fibers/unsaturated polyester composites. J Colloid Interf Sci 2001 Oct;242(1):174-179.

15. Perdigão J, Gomes G, Lee IK. The effect of silane on the bond strengths of fiber posts. Dent Mater 2006 Aug;22(8): 752-758.

16. Wrbas KT, Schirrmeister JF, Altenburger MJ, Agrafioti A, Kielbassa AM. Influence of adhesive systems on bond strength between fiber posts and composite resin cores in a pull-out test design. Dent Mater J 2007 May;26(3):401-408.

17. Mosharraf R, Ranjbarian P. Effects of post surface conditioning before silanization on bond strength between fiber post and resin cement. J Adv Prosthodont 2013 May;5(2):126-132.

18. Aksornmuang J, Foxton RM, Nakajima M, Tagami J. Microtensile bond strength of a dual-cure resin core material to glass and quartz fiber posts. J Dent 2004 Aug;32(6):443-450.

19. Mosharraf R, Haerian A. Push-out bond strength of a fiber post system with two resin cements. Dent Res J (Isfahan) 2011 Dec;8(Suppl 1):S88-S93.

20. Mjör IA, Smith MR, Ferrari M, Mannocci F. The structure of dentine in the apical region of human teeth. Int Endod J 2001 Jul;34(5):346-353.

21. TopcuFT,Erdemir U,Sahinkesen G, MumcuE, Yildiz E, Uslan I. Push-out bond strengths of two fiber post types bonded with different dentin bonding agents. J Biomed Mater Res B Appl Biomater 2010 May;93(2):359-366.

22. Gwinnett AJ. Quantitative contribution of resin infiltration/ hybridization to dentin bonding. Am J Dent 1993 Feb;6(1):7-9. 